\title{
RESENHA: DE ROMÂNTICO E LOUCO...
}

\author{
Débora Racy Soares ${ }^{1}$
}

Poetas Românticos, Críticos e Outros Loucos ${ }^{2}$ é uma coleção de ensaios de Charles Rosen. Dividido em duas partes, os dez ensaios que compõem o livro enfocam o período romântico através de alguns textos fundamentais. Escritos em línguagem acessível, o que não é sinônimo de simplificação ou concessão, os ensaios do pianista, crítico literário e professor de música e teoria social da Universidade de Chicago, jamais escorregam para certo hermetismo mofado, nada incomum aos escritos acadêmicos. Estes ensaios, gerados ao longo de vários anos, conduzem o leitor por caminhos inusitados que, além de surpreender, revelam um passeio orientado pelo prazer ao texto.

Logo na introdução, Rosen revela seu fascínio (e certo desconforto) pela ambigüidade da crítica nas artes. Mesmo quando os limites da crítica são freqüentemente testados pelo autor, seu entusiasmo mantém-se inabalável. Pouco importa se este entusiasmo advém da paixão com que se debruça sobre os assuntos eleitos ou da satisfação de suas descobertas. O fato é que a retórica apaixonante de Rosen não só contagia o leitor como também dá novo fôlego à crítica artística. Na introdução já está anunciada uma das questões que norteiam estes escritos: a problematização do julgamento estético. Rosen ancora seus textos em mares antes navegados pelos irmãos Schlegel e Novalis, os primeiros românticos de Iena. Mas é desvendando alguns procedimentos críticos que o autor nos leva a desconfiar de certa crítica, contumaz decifradora, que insiste em solucionar os segredos ocultos nas obras de arte. Crítica um tanto "críptica", para usar a expressão de um poeta brasileiro, que delineia elucubrações muito questionáveis, ancorada em boa dose de misticismo e muita imaginação.

A escolha dos temas revela a formação eclética do autor que versa com desenvoltura sobre cartas, revisões, pontuação, livro de receitas, partituras, poetas, entre outros. O livro é uma verdadeira mélange que abrange várias artes, no melhor estilo inclusivo ("universal progressivo"?) dos primeiros românticos.

\footnotetext{
1 Universidade Estadual de Campinas (UNICAMP), Doutoranda do Programa de Teoria e História Literária, Literatura Brasileira, Poesia.

2 Poetas Românticos, Críticos e Outros Loucos. Campinas: Ateliê Editorial, Editora da Unicamp, 2004. 276 págs.
} 
Os seis ensaios da primeira parte estão reunidos sob o sintomático título "Ilusões Românticas" e desmistificam certos topoi comuns ao romantismo. O primeiro ensaio, por exemplo, versa sobre a revisão dos textos para as edições críticas e desvenda a incoerência de certos editores em busca do texto definitivo. Rosen parte de um conto de Balzac, "Le Chef d'oeuvre inconnu", que encena o drama de um pintor (Frenhofer) incapacitado de terminar sua obra. Com o intuito de torná-la absolutamente perfeita, ele a vinha repintando há dez anos, sem perceber que sua obsessiva revisão acabaria por destruí-la. Balzac, que ao contrário de Frenhofer, não era autor de um livro só, também parece ter sofrido do mal da revisão. Segundo Rosen, a revisão sistemática feita por Balzac, ironicamente deste mesmo conto, acabou por alterar substancialmente seu significado. Publicado inicialmente em 1831, na revista "L'Artiste", o conto receberia acréscimos em 1837, revelando, como quer Rosen, que "a revisão na arte romântica se desloca da experiência direta para uma reflexão mediada" (p.19). Após essa constatação inicial, o autor explora a função e os aspectos de uma edição crítica através de rápida viagem pelos séculos. A edição crítica é aquela que apresenta os estágios de desenvolvimento de uma dada obra, desde o seu manuscrito até as sucessivas edições, de forma a abarcar todas as suas variantes. É interessante, porém breve, a historinha das edições críticas apresentada por Rosen. Ficamos sabendo, por exemplo, que nos séculos XV e XVI as notas apensas de uma obra antiga não eram somente impressas em pé de página, mas também no alto e nas margens. A formatação das letras do texto principal, que era rodeado por comentários extraídos de fontes diversas, seguia um padrão maior do que as notas. Os textos de Virgílio ou de Petrarca, bem como os Evangelhos eram margeados por comentários cuja função era oferecer o contexto dos escritos. Em meados do século XVIII, era moda corrigir o texto de um autor grego ou latino. Como aponta Rosen, criou-se, nesta época, uma "importante indústria acadêmica" em torno dos estudos clássicos que pareciam fadados ao lançamento de "edições melhoradas" visando a "estabelecer um texto definitivo" (p.21). Alguns métodos de correção e editoração foram sistematizados no século XIX e os comentários passaram a ser impressos em nota de rodapé ou separados do texto. A ambição dos corretores incluía a correção dos "inumeráveis erros" de Shakespeare e Dante o que, além de causar muita querela - já que os corretores não conseguiam entrar em acordo quanto à versão mais "aceitável" dos textos - atestava a falência de um projeto que iria se tornar um empreendimento individual e especializado (p.21). No século $\mathrm{XX}$, as notas foram definitivamente deslocadas para o fim do livro ou do capítulo, procedimento que adotamos até hoje. As editoras que geralmente optam por apresentar o texto desafogado de suplementos explicativos, com a velha desculpa de que devemos nos concentrar na obra, não estariam apostan 
do em um conceito equivocado de texto puro ou definitivo? Rosen não só acredita que sim, como vê nessa esterilização impositiva um "grande empecilho" para a edição crítica das obras. Afinal, no que concerne aos autores clássicos, buscar um texto único é tentar minimizar os erros cometidos por sucessivos copistas. De qualquer forma, diante de Platão, Sófocles ou Sêneca restam apenas diversas versões adulteradas de um texto copiado. No caso das obras modernas, a finalidade de uma edição crítica é multiplicar as versões, ajudando-nos a compreender a gênese do texto e a maneira com que o recebemos. Se o editor de um texto clássico opera com a síntese, o de um texto moderno trabalha no terreno da análise ou decomposição. Ou como diz Rosen, o editor de uma obra clássica constrói um texto único, normalmente fictício. Já o editor de um Balzac ou de um Wordsworth desmembra o texto único em uma "série cronológica de textos" (p.23). Mas nem sempre a operação desmembramento é bem-vinda. No caso dos Ensaios de Montaigne, cuja segunda edição, de 1588, era uma ampliação vigorosa da primeira, pois interpolava várias camadas de composição em um estilo que era capaz de captar o movimento do pensamento do autor, o preciosismo dos detalhes comprometia a legibilidade do texto. Já no caso de poemas em que as correções são intensas, as primeiras e as últimas versões são tão distintas que não mais correspondem à mesma obra. Esses casos, embora raros, acontecem. Haja vista a versão de um poema de Byron que no manuscrito correspondia a 334 versos, alcançando os 684 versos no momento de sua primeira publicação. Como se não bastasse, na segunda edição, lançada somente seis meses depois da primeira, Byron acrescentou outros 650 versos e desistiu de fazer novos acréscimos. Em situações como essas, diz Rosen, as casas editoriais se deparam com dois "fetiches bibliográficos". O primeiro pressupõe a escolha do "texto a publicar" que, embora não importe muito para a maioria dos livros, em casos raros, causa dor de cabeça aos editores (p.27). Os exemplos clássicos são Rei Lear e Hamlet de Shakespeare e as obras poéticas de Pierre de Ronsard cujas variantes, por serem conflitantes, exigem a impressão integral de todas as versões. $\mathrm{O}$ outro fetiche é a crença comum de que a versão final do autor teria a máxima autoridade e, portanto, deveria ser privilegiada. Segundo Rosen, a cartilha dos direitos autorais reza que autor morto, mesmo há mais de um século, ainda pode decidir sobre qual versão de sua obra quer publicar. Há alguns casos extremos em que as sucessivas versões de uma mesma obra tendem a enfraquecer ou até trair a idéia contida na original. O século XIX parece ser pródigo em exemplos de deterioração progressiva de obras, o que acarretaria, no limite, um problema de estilo. Wordsworth, apesar de acreditar que a revisão mais piorava do que melhorava seus textos, não deixou de fazê-la. Seu intuito era apagar os indícios de tendências religiosas e políticas que acreditava comprometer seus 
escritos de juventude. Se Goethe pensava que a arte romântica era uma doença, em certo sentido ele parecia estar certo. Como diz Rosen, algumas tentativas de correção ou higienização de um texto terminam por destruir o essencial do primeiro rascunho. Nesse sentido, se as revisões traem a intenção original da obra, estamos próximos da crença romântica na "importância da vontade inconsciente na criação" (p.39). Não foram poucos os autores que revelaram sua total falta de domínio sobre as obras que, em um dado momento, pareciam ganhar fôlego próprio. Este ensaio de 1987 é acompanhado de um adendo, escrito onze anos depois, em que Rosen, mais do que acrescentar dados novos, discute uma das polêmicas suscitadas por seu texto. Que fique claro: não se trata de uma revisão bem humorada, mas da emersão de pontos anteriormente subentendidos.

O artigo seguinte, oriundo de uma resenha escrita em 1973, enfoca o programa messiânico dos primeiros românticos, a partir das idéias de William Empson e de David Pirie. Este programa messiânico, explica Rosen, em que a política e arte não se separavam, tampouco se diferenciavam, promovia a permanência de um estado de natureza que antes era transitório. Apoiado no clássico livro de M. H. Abrams, Mirror and the Lamp, visando a compreender a recorrente metáfora romântica da "jornada sinuosa", Rosen se pergunta se os padrões do pensamento romântico seriam mesmo teológicos como Abrams afirmara. Diante da generosa expansão do sentido de religioso, Rosen atenta para a necessária avaliação da relação que cada poeta do primeiro romantismo estabelecia com a religião. Se Abrams acertou ao afirmar que a utilização do léxico religioso não dependia da crença dos poetas românticos, Rosen procurou compreender as implicações sociais inerentes à escolha deste léxico. Como Empson e Pirie sustentam, Coleridge modificara um poema escrito em 1798 de forma a trair seu primeiro significado. Utilizando padrões narrativos religiosos como "casca exterior", Coleridge revelaria, pela análise de Rosen, um sentimento profundamente anti-religioso para os padrões da época (p.54). Através da análise poética de Coleridge, Rosen demonstra a maneira com que alguns românticos privavam as formas de seu significado original, atribuindolhes um novo sentido, muitas vezes oposto ao primeiro. É no embate com as idéias de Abrams que o ensaio de Rosen ganha fôlego. A omissão por Abrams de alguns românticos irônicos, como Byron e E. T. A. Hoffmann, acrescida de sua incapacidade - atribuída a seu esquema teológico - de encarar o final de Hyperion de Hölderlin como uma "nova forma de morte", não passam despercebidas ao olhar agudo de Rosen (p.59).

Trilhando as cartas de Flaubert à sua amante Louise Colet, Rosen atesta o pouco caso que a posteridade teria atribuído a uma distinção essencial: a separação entre arte e vida. Este será o tema do ensaio seguinte em que Rosen, 
além de dialogar com Flaubert e Victor Hugo, discorre também sobre a pontuação romântica. A concepção romântica da arte enquanto "documento puramente pessoal e inteligível para qualquer um, exceto o autor" será posta em xeque neste ensaio (p.72). Flaubert já dissera em suas cartas que "envolvidos na vida, nós a vemos mal". Talvez por esta razão concebesse o artista como uma "monstruosidade, alguma coisa fora da natureza" (p.68). Rosen discorre sobre o grotesco em Victor Hugo e Flaubert, demonstrando como o autor de L'Éducation Sentimentale percebe esta característica esvaziada de qualquer significação cultural. Sua concepção de grotesco imporia, segundo Rosen, uma concepção clássica de beleza, livre porque isenta de qualquer forma de pressão. As cartas de Flaubert, ao invés de atestarem a separação entre arte e vida, revelariam sua junção. Se a obra é produto "tão absolutamente natural que não pode elevar-se ao nível do artifício", o artista"monstro" deve "permanecer dentro da esfera da compreensão totalmente subjetiva" (p.72). Mas há paradoxos fascinantes nas teorias estéticas de Flaubert que devem, como diz Rosen, ser "engolidos" se quisermos penetrar em seus escritos. Um deles, por exemplo, reclama ao "produto subjetivo uma objetividade quase científica" (p.72). Os romances tinham para Flaubert um estatuto histórico bem determinado. Eram considerados documentos, testemunhos precisos e imparciais de realidades objetivas, apesar da intensidade subjetiva. Já suas cartas, preocupadas em grande parte com a teoria da literatura, careciam de subjetivismo e abundavam em jogos de imaginação. Os limites da obra de arte são constantemente problematizados, através da dificuldade em se estabelecer fronteiras entre a arte e a vida e até mesmo entre os gêneros artísticos. Rosen adverte ainda, a partir de Byron, que a confusão entre biografia e arte, implícita nos primeiros românticos, é favorecida pela dificuldade em se separar os escritos públicos dos privados. Mas nessa questão, todo cuidado é pouco. Afinal, a subjetividade romântica não é necessariamente expressão pessoal. Como atesta Rosen, no caso de Wordsworth "as manifestações mais impressionantes são profundamente impessoais" (p.83).

Livros de receitas são o tema do próximo ensaio, mais especificamente o importante Mediterranean Food de Elizabeth David. Responsável pela transformação dos hábitos alimentares da alta classe média britânica, este livro é concebido mais como livro de viagem do que de receitas. Embora o meio de expressão básico da autora seja a receita, suas instruções tendem a ser lacônicas. O livro considerado bom, o é justamente porque pretende mais inspirar futuros cozinheiros e atuais comedores, do que oferecer técnicas culinárias. A autora envereda por lembranças de lugares visitados e pratos degustados, mobilizando a visão, o olfato e o paladar dos leitores que não resistem diante de 
receitas tão simples de preparar. A dificuldade maior parece ser encontrar os condimentos necessários: o purê de tomates feito com tomates amadurecidos no pé, a manjerona fresquinha, apanhada na hora, o azeite de oliva bem prensado. O grande prazer, diante da dificuldade de preparação da receita, é a viagem a um passado remoto. É pela oferta de uma reminiscência feliz que Rosen considera Elizabeth uma autora de pastorais. A pastoral é uma "forma literária que evoca uma idade de ouro, uma época em que a vida era descomplicada e os prazeres eram simples" (p.96). A nostalgia do passado mítico talvez possa ser amenizada pelos odores que emanam da cozinha e pelo ato simbólico de comer. Um livro que deve ser degustado, senão à luz de velas, no melhor estilo de um "último suspiro do movimento romântico" (p.97).

Em "Códigos Secretos", Rosen discorre sobre duas de suas paixões: a música e a pintura. Partindo do compositor Robert Schumann e do paisagista Caspar David Friedrich, o autor registra as dificuldades que a ambigüidade provocou na interpretação da arte romântica. O princípio fundamental do simbolismo romântico, diz Rosen, é que o sentido não pode jamais se separar de sua representação simbólica, portanto, a imagem não pode nunca ser reduzida a uma palavra. Entretanto, alguns críticos de Friedrich insistem em decifrar sua estratégica pictórica através da procura por códigos que revelariam um "idioleto" pessoal encoberto. Como qualquer outra arte, suas pinturas resistem à tradução e podem apenas ser interpretadas. Se cada imagem que figura em seus quadros tem um sentido particular, pautar o entendimento de sua pintura pela decifração de um "código esotérico" seria, no limite, "falsificar" sua arte (p.108). Já no caso de Schumann, grande parte da pesquisa em torno de sua obra perde força quando tenta procurar analogias entre a obra e a vida. A confusão se dá porque sua obra é fortemente marcada por uma expressão pessoal que, ao soar incomunicável, parece ter sido composta como "brincadeira para iniciados" (p.110). As partituras de Schumann são criadas em uma "região penumbrosa em algum lugar entre a arte e a vida" e são pautadas pela teoria romântica das relações entre as artes (p.110). Em outras palavras, Schumann criara uma técnica musical que permitiria à música incorporar recursos literários, como os anagramas, sem deixar de ser música. O mesmo caso acontecia com as "aspas musicais" e as citações, cuja função era "soar como uma intromissão vinda de fora da obra" (p.115). É interessante perceber como agem os efeitos programáticos - aqueles que fazem remissão a um sentido extra musical, em Schumann. Se em Haydn, Beethoven ou Strauss estes efeitos podem facilmente ser traduzidos por imagens ou palavras, em Schumann não "há possibilidade de intrusão verbal entre a música e seu significado" (p.117). Sua música pode ser interpretada, mas não traduzida, já que suas ressonâncias poéticas deslocam qualquer significação extra musical. Neste momento, Rosen 
desfia uma crítica ferina aos críticos que buscam "códigos privativos" de significação ou compilam "glossários de significados" visando a traduzir as obras, isto é, a "substituir um signo ou conjunto de signos por outro", isolados de qualquer situação ou contexto (p.119). Neste caso, o que se faz é impor significados arbitrários, de fora para dentro. Se a arte insiste na unicidade da cada uso de um símbolo, querer estabilizar sentidos é ignorar que a possibilidade da arte está "a todos tempo presente na línguagem" (p.120). Ninguém tinha mais consciência disso do que os poetas e artistas do início do século XIX. Para eles tudo era línguagem, portanto, arte em potencial. Esta visão radicalmente nova da línguagem impossibilitaria e até atestaria, por exemplo, o fracasso de um "dicionário de iconografia romântica" (p.120). Nunca é demais lembrar que a interpretação de cada obra sempre deve nascer de dentro para fora. O caminho oposto conduz tão-somente a generalizações facilitadoras que menos iluminam do que frustram.

Em "Poetas Loucos", ensaio que conclui a primeira parte, Rosen procura demonstrar como, paradoxalmente, a "insanidade era saudável" para os românticos (p.131). Os poetas eleitos para análise são: William Cowper, Christopher Smart e Friedrich Hölderlin. O primeiro sofria de depressão e integrava o grupo de jovens escritores que fundaram o Nonsense Club. No limite do desespero afirmara que a loucura era a "única chance" que lhe restara (p.125). Internado em um asilo para se tratar, Cowper tentara, sem sucesso, o suicídio. Vizinhos, amigos e parentes atribuíam suas crises à dificuldade de encarar suas responsabilidades. Subterfúgio ou não, o fato é que Cowper acreditava que Deus lhe ordenara, em sonho, que se suicidasse e ele era incapaz de fazê-lo. Se a loucura para Cowper, como para Blake, era uma fuga, ela "deu-lhe o ócio de que carecia para escrever seus poemas e suas correspondências" (p.127). A loucura virara "moda entre 1750 e 1850", pois era "fonte de energia criativa" (p.132). Rosen acredita que, para a maioria dos escritores, ela era um "ideal e um anti-ideal". Mais do que um colapso do pensamento racional, a loucura promovia "diferentes insights" e outros modos de raciocinar (p.132). Smart, que publicou sua obra-prima (A Song to David) após deixar o asilo, ouviu dos críticos que "estava doido como sempre" (p.139). Porém, como demonstra Rosen, a loucura o ajudou a "encontrar sua voz original" (p.141). Já em Hölderlin, a loucura se afigurava como "passaporte para um mundo perdido" (p.142). A utilização do panteão grego, em seus hinos e elegias, como uma representação das forças naturais universais, evidencia que o poeta de Pão e Vinho "aceitava a existência dos antigos deuses" (p.141). Se muitos poetas foram descartados em sua época por terem sido considerados loucos, a crítica do século XX tem procurado reavaliá-los, demonstrando a vitalidade de suas obras. 
A segunda parte do livro, intitulada "Aproximações da Crítica", consiste em quatro ensaios com temáticas várias. O primeiro deles é oriundo de uma resenha sobre o conhecido Origem do Drama Trágico (Trauerspiel) Alemão de Walter Benjamin. Rosen parte da tese de qualificação do filósofo-crítico, rejeitada pelos membros da congregação da Universidade de Frankfurt que declararam não ter entendido uma palavra sobre o texto - para elucidar seus princípios críticos. Ao mesmo tempo, retoma a tese de doutorado de Benjamin sobre a crítica de arte no romantismo alemão, apontando os equívocos críticos na compreensão do autor. Equívocos, em parte, decorrentes da línguagem descontínua de seus escritos que, embora sustentem sua aura, dificultam sua compreensão. Rosen retoma algumas das questões desenvolvidas anteriormente, na primeira parte do livro. Neste ensaio o enfoque recai sobre a relação biografia e obra que é pensada na clave benjaminiana da pré e da pós-história das obras de arte. No caso da literatura, o crítico que pretende dar conta desta dupla natureza da obra, precisa lançar mão de dois modos de aproximação: o comentário e a crítica. Na cartilha de Benjamin, o comentário contemplaria a impressão da vida passada evocada pela obra, enquanto que à crítica caberia entender como a obra se destacaria daquela vida. Se o método do comentário é filológico, o da crítica é filosófico e ambos são interdependentes. No Trauerspiel Benjamin põe em prática esta dupla metodologia e ainda revela um "segredo esotérico" (p.175). Para Benjamin toda obra de arte precisava se tornar uma ruína para preservar sua natureza essencial. A obra de arte autêntica, entendida como uma encarnação metafórica de idéias filosóficas, já não existe por si mesma, mas em função daquelas idéias que a sustêm. Nesse sentido, a tarefa do crítico que entende a obra como ruína é ir ao encontro das idéias essenciais da obra, sem "ressuscitar os mortos" ou "reconstituir o original" fragmentado (p.175). Para tanto, Benjamin precisou inventar para a crítica uma metodologia baseada em uma filosofia radical da línguagem, do conhecimento e da história.

No ensaio seguinte, Rosen ocupa-se dos códigos secretos ou das estruturas escondidas na música e na literatura, como fizera em artigo anterior. $\mathrm{O}$ autor parte dos gráficos de Heinrich Schenker - herdeiro musical dos grandes críticos literários do início do século XIX - para demonstrar como ele desprezava compositores que não se enquadravam em suas teorias musicais. Bach, Haydn, Chopin e Brahms eram considerados inferiores, enquanto Stravinski e Reger era sumariamente descartados e confinados ao limbo porque suas tonalidades eram consideradas dissonantes. O esquema de Schenker reduz a obra musical a uma linha que é descida para a nota central ou tônica e embaixo de cada nota da linha as funções harmônicas são indicadas por uma grave. A música que não se encaixava em sua estrutura era considerada incoerente ou antigramati 
cal. Em seu ponto de vista, toda obra tonal era o desenvolvimento de uma simples cadência. A cadência, elemento determinante na música ocidental desde o canto gregoriano até o início do século XIX, é um esquema que molda e define uma composição musical. Seu método de análise desvela "uma forma oculta e secreta subjacente à explícita" (p.210). Ele reconhece que existem formas como a sonata, o rondó, mas nega que elas tenham importância. No seu modo de ver, a forma implícita é a única válida porque revela como a música foi composta. Passemos da música à literatura. Ferdinand de Saussure, ao morrer em 1922, deixou noventa e nove cadernos recheados de anotações sobre anagramas ocultos na poesia latina. Alguns trechos dos cadernos, que tiveram publicações esparsas, mostram que o ponto de partida de Saussure foi a investigação da estrutura fonética do verso saturnino latino. A importância desses cadernos, que merecem vir a público na íntegra, demonstram a estreita relação entre a poesia e os processos lingüísticos. A "poesia da gramática" de Jakobson ainda é suscitada como forma de entender a relação entre o explícito e o implícito na línguagem. Rosen atenta para o descuido de certa crítica que tem ignorado a significação implícita das obras de arte, incorrendo em análise redutora. A lição de Benjamin discutida no ensaio anterior deve, portanto, iluminar os críticos de arte.

O ensaio seguinte discorre sobre William Empson, um dos melhores críticos de literatura inglesa na opinião de Rosen. Suas idéias causaram protestos e furor em sua época por revelarem à sociedade temas difíceis de encarar. Em seu The Structure of Complex Words procurou demonstrar como a ambigüidade da línguagem revelava nossos "desejos e preconceitos nãoreconhecidos" (p.236). Empson acreditava que a função do artista era revelar "tensões e contradições inconfessadas", de modo a conduzir seus leitores a um melhor conhecimento de suas culturas e até de si mesmos.

O último ensaio do livro é sobre a crítica musical de George Bernard Shaw. Ele que considerava a crítica "mera perda de tempo" e cujo principal objetivo "não era fazer justiça", posava de polemista e gozador. Na opinião de Rosen, talvez seja o maior de todos os críticos de música, apesar do nonsense em que pautava suas análises. No caso de Shaw e de outros críticos de sua época, Rosen revela que a justeza da avaliação importava menos do que a política da crítica.

No quesito crítica, Rosen segue a tradição dos primeiros românticos. É um leitor apaixonado que rumina. Para os que se interessam pelo assunto e querem ampliar a discussão, não percam A Geração Romântica (Edusp, 2000). 


\section{REVISTA CONEXÃO LETRAS Política Editorial}

A Revista Conexão Letras do Programa de Pós-Graduação em Letras da Universidade Federal do Rio Grande do Sul publica estudos de base teórica e aplicada nas áreas de Lingüística e Literatura, com produção semestral alternada: um semestre para estudos literários, outro para estudos lingüísticos, sendo que possui, simultaneamente, produção on-line e forma impressa. Aceitam-se colaborações do Brasil e do exterior, desde que se trate de pesquisa original desenvolvida dentro das referidas áreas.

A Revista publica textos em forma de artigos, debates, entrevistas sob forma de debate e resenhas, sendo aceitos para publicação trabalhos nas línguas portuguesa, francesa, inglesa e espanhola.

As diferentes modalidades de publicação devem obedecer às normas que seguem

a) Artigos: textos entre 15 e 30 páginas, contendo Introdução, Análise (subdividida em itens) de acordo com a natureza da pesquisa, e Considerações Finais.

b) Retrospectivas: textos entre 15 e 30 páginas, envolvendo reflexões críticas a respeito de percursos de teorias ou pressupostos implicados na trajetória de escolas lingüísticas e literárias.

c) Debates: textos entre 10 e 15 páginas, contendo diálogos sob forma de abordagem de questões relativas a outros estudos já publicados, tais como: contribuições relevantes, limites e aspectos críticos do estudo em análise.

d) Entrevistas Sob Forma de Debate: textos entre 15 e 30 páginas, contendo diálogos com outros pesquisadores, os quais envolvam diferenças de enfoque teórico e contradições em torno de um mesmo tema, ou análise crítica sobre o estado da pesquisa realizada nas áreas de publicação da Revista.

e) Resenhas: textos entre 4 e 10 páginas, contendo análise e reflexões críticas a respeito de livros publicados no país e no exterior.

\section{Normas Para Apresentação de Trabalhos}

Os artigos, retrospectivas, debates e entrevistas sob forma de debate serão precedidos por Abstract, Résumé ou Resumen e seguidos por Resumo com aproximadamente 150 palavras cada

Serão constituídos por:

- Título do Trabalho em letra maiúscula.

- Abstract, Résumé ou Resumen, seguido de Resumo em Língua Portuguesa, com espaço simples e um intervalo de espaço duplo entre cada

- As expressões Key-words, Mots-clé, Palabras-clave, contendo, no máximo, 5 itens, seguidas de Palavras-chave (espaço simples entre as referências em línguas estrangeira e portuguesa).

- Introdução e Considerações Finais sem numeração

- Corpo do trabalho numerado em diferentes seções, conforme a natureza da pesquisa.

- Citações de até 4 linhas, entre aspas, no corpo do trabalho, podem manter o mesmo padrão deste. Citações de mais de 4 linhas que ocupem parágrafo próprio, deverão ser digitadas em fonte 10 , itálico, com recuo de dois toques, com espaço 1,5 em relação ao corpo do texto.

- Notas devem ser digitadas em pé de página (corpo 10).

- As referências bibliográficas devem estar em ordem alfabética e obedecer a ordem cronológica de publicação, no caso de haver várias obras de um mesmo autor, de acordo com os seguintes critérios: sobrenome do autor, nome, seguido de ponto., título do livro ou revista em itálico e somente com a letra inicial em maiúsculo, seguidos de ponto, local de publicação, seguido de vírgula, data de publicação e indicação de páginas e vol.,( no caso de revista ou de coleção), conforme os modelos a seguir: LYONS, John. Introdução à lingüística teórica. São Paulo, Ed. Nacional, 1979. COURDESSES, Lucile. Blum et Thorez em may 1936: analyses d'enoncés.In:Langue française.Paris, Ed. Larousse, vol.9, p.23-33,1971.

- Tabelas, gráficos e desenhos devem ser encaminhados em versão também impressa, pronta para reprodução.

Os trabalhos serão enviados em disquete, versão recente de Word for windows, Times New Roman, corpo12, espaço simples acompanhados de duas cópias impressas. Em folha anexa, devem ser apresentados os dados de identificação do colaborador, tais como: Nome do pesquisador, Instituição, Áreas de trabalho, Endereço, Telefone, Fax, E-mail

Os colaboradores receberão dois exemplares da Revista por ocasião da publicação.

Os textos não aceitos para publicação não serão devolvidos aos autores, que serão informados sobre o resultado da avaliação realizada por dois pareceristas, membros do Conselho Editorial

Comissão Editorial

Ana Zandwais - UFRGS

Jane Tutikian - UFRGS

Lúcia Sá Rebello- UFRGS
Os trabalhos devem ser remetidos para

Revista CONEXÃO LETRAS

Programa de Pós-Graduação em Letras - UFRGS

Comissão Editorial

Av. Bento Gonçalves 9500 Bairro Agronomia

Porto Alegre - CEP 91540.000

192 VOLUME 2, NÚMERO 2, 2006 